\title{
Sorption of 2,4,6-Trichlorophenol in Model Humic Acid-Clay Systems
}

\author{
XIaO-PIng Wang, ${ }^{\dagger, \dagger}$ XIaO-Quan Shan, $,{ }^{*},{ }^{\dagger}$ Lei Luo,${ }^{\dagger}$ Shu-Zhen Zhang,${ }^{\dagger}$ And \\ BEI WEN ${ }^{\dagger}$
}

State Key Laboratory of Environmental Chemistry and Ecotoxicology, Research Center for Eco-Environmental Sciences, Chinese Academy of Sciences, P.O. Box 2871, and Institute of Tibetan Plateau Research, Chinese Academy of Sciences, Beijing 100085, China

\begin{abstract}
Humic acids and clays are important soil components that influence the sorption and desorption of organic contaminants; however, it is unclear how humic acids influence the sorption of organic contaminants onto clays and their subsequent desorption. Sorption and desorption of 2,4,6trichlorophenol (2,4,6-TCP) by and from humic acid-modified $\mathrm{K}^{+}$- and $\mathrm{Ca}^{2+}$-montmorillonite and -illite were compared with unmodified clays using batch equilibration methods. Commercial humic acid and the humic acid extracted from forest soil were employed in this experiment. The adsorbed amount of 2,4,6-TCP by commercial humic acid was almost twice as large as that adsorbed by the extracted soil humic acid. More 2,4,6-TCP was sorbed onto $\mathrm{K}^{+}$- and $\mathrm{Ca}^{2+}$-illite than onto $\mathrm{K}^{+}$- and $\mathrm{Ca}^{2+}$ montmorillonite. $\mathrm{K}^{+}$clays were more effective in adsorbing 2,4,6-TCP than $\mathrm{Ca}^{2+}$ clays. Sorption of 2,4,6-TCP on humic acid-modified $\mathrm{Ca}^{2+}$ - and $\mathrm{K}^{+}$-montmorillonite and -illite increased as compared with unmodified clays. The sorption nonlinearity of 2,4,6-TCP on humic acid-modified $\mathrm{Ca}^{2+}$ - and $\mathrm{K}^{+}$illite increased remarkably as compared with the unmodified clays. The sorption nonlinearity of 2,4,6TCP on humic acid-modified $\mathrm{Ca}^{2+}$ - and $\mathrm{K}^{+}$-montmorillonite increased slightly in contrast to unmodified montmorillonites. By comparing sorption and desorption results, we observed hysteresis for all sorbents including humic acids, clays, and humic acid-modified clays. Sorption nonlinearity and hysteresis were dependent on the structure of humic acids. Higher aromaticity of humic acids resulted in greater sorption nonlinearity and desorption hysteresis. In addition, sorption capacity $\left(K_{\mathrm{f}}^{\prime}\right)$ was positively correlated with the humic acid content of the sorbents. These results show that modification of humic acids on clays can not only increase the adsorption ability of clays but also affect the sorption nonlinearity of 2,4,6-TCP, and the desorption hysteresis was probably due to the structural characteristics of humic acids.
\end{abstract}

KEYWORDS: Sorption and desorption; 2,4,6-trichlorophenol; humic acid-modified montmorillonite and illite

\section{INTRODUCTION}

In soil, organic matter and minerals are often associated such that it is unclear how the presence of the former influences the sorption and desorption properties of the latter. Sorption and desorption are important processes that influence the mobility, bioavailability, and toxicity of organic contaminants in the soil environment. Soil organic matter (SOM) content, surface characteristics, $\mathrm{pH}$, soil texture, and clay minerals affect the retention of organic contaminants $(1-3)$, with soil minerals and SOM being the major components influencing the sorption of organic contaminants including pesticides.

* To whom correspondence should be addressed. Tel: +86-10-62923560.

Fax: +86-10-62923563. E-mail: xiaoquan@mail.rcees.ac.cn.

Research Center for Eco-Environmental Sciences.

$\doteqdot$ Institute of Tibetan Plateau Research.
Pesticide distribution patterns in soil are controlled by adsorption and partitioning. Pesticides in the liquid phase are readily available for plant uptake, and it is well-established that the uptake of nonpolar organic contaminants from aqueous solution is strongly correlated with soluble organic matter (or organic C) contents (4-8). Reliance on SOM-normalized sorption coefficients $\left(K_{\mathrm{om}}, K_{\mathrm{oc}}\right)$ to predict the transport of organic contaminants in soil implied that SOM is the sole sorption domain but ignored the potential contributions of soil mineral fractions. Mingelgrin and Chiou $(9,10)$ noted that soil behaves as a dual sorbent, in which SOM functions as a partitioning medium and mineral fractions as conventional adsorbents. However, for moderately and strongly polar functional groupcontaining compounds including many pesticides, multiple sorption mechanisms may be operative $(11,12)$. The relevant mechanisms include solute partitioning into SOM as well as 
specific interactions with mineral components such as clays (13, 14). In some cases, mineral fractions may show a stronger ability on the adsorption and desorption of organic contaminants and pesticides than SOM (15).

Desorption hysteresis of organic contaminants from soils and sediments has been recognized due to its importance for understanding of the transport of organic contaminants in the environment. Desorption hysteresis constrains the bioavailability of organic contaminants in soils $(16,17)$, and it may effectively reduce the mobility of contaminants in the environment, thereby increasing environmental sequestration and resistance.

2,4,6-Trichlorophenol (2,4,6-TCP) is used as an antiseptic, a pesticide for wood, leather, and glue preservation, and as an antimildew treatment. 2,4,6-TCP has been shown to be carcinogenic for animals, producing lymphomas, leukemia, and liver cancer via oral exposure (18). 2,4,6-TCP exposures may occur through drinking water or food. Information regarding 2,4,6TCP sorption and desorption characteristics in soil is necessary to predict its fate in the soil environment. Sorption brings to the sequestration of 2,4,6-TCP in soil, and desorption may give potential concentration increases of 2,4,6-TCP in soil solution and further lead to toxic effects on freshwater. Hence, it is important to investigate the sorption/desorption process of 2,4,6TCP in the soil/soil solution interface. The sorption behavior of 2,4,6-TCP in some sorbents has been investigated. For example, information concerning competitive sorption of 2,4,6TCP with other chlorophenols in activated carbon (19) and TCP sorption characteristics under aerobic and anaerobic conditions in soils (20) provides useful evidence for its fate in the soil environment.

SOM and clays are often associated together. However, the influences of SOM and clay minerals on the sorption and desorption of organic pollutants are poorly understood $(21,22)$. In this study, the sorption and desorption behaviors of 2,4,6TCP on and from humic acid-modified $\mathrm{Ca}^{2+}$ - and $\mathrm{K}^{+}$-montmorillonite and -illite and unmodified ones were compared. The possible effects of humic acids and clays on the sorption of 2,4,6-TCP on the humic acid-clay system were discussed.

\section{MATERIALS AND METHODS}

Sorbates. 2,4,6-TCP was purchased from Aldrich Chemical Co. Inc. (Milwaukee, WI) with a reported purity of $>98 \%$. Anhydrous calcium chloride, $\mathrm{KCl}$, and $\mathrm{HCl}$ were reagent grade, and methanol was highperformance liquid chromatography (HPLC) grade, which was used for HPLC determination of 2,4,6-TCP. 2,4,6-TCP has a $\log K_{\text {ow }}$ of 3.64.05 and a solubility of $434 \mathrm{mg} \mathrm{L}^{-1}(23)$.

Sorbents. Two types of humic acids were employed in this study. One humic acid $\left(\mathrm{HA}_{1}\right)$ was purchased from Tianjing Chemical Factory (Tianjing, China), which was extracted from peat. Another $\left(\mathrm{HA}_{2}\right)$ was laboratorially extracted from forest soils following the procedure outlined by Swift (24).

The reference illite and montmorillonite were obtained from Youlichuangjia Technologies (Beijing, China) and used just as received without any further purification. The preparation of $\mathrm{Ca}^{2+}$ - and $\mathrm{K}^{+}$saturated illite, montmorillonite, and humic acid-coated illite and montmorillonite followed the procedures described by $\mathrm{Li}$ (12). The clay fractions were washed with $0.5 \mathrm{M} \mathrm{KCl}$ solution four times. The excess $\mathrm{KCl}$ was repeatedly washed away with Mill-Q water until no $\mathrm{Cl}^{-}$was detected. The same procedures were employed for the preparation of $\mathrm{Ca}^{2+}$-saturated clays; however, in this case, $0.5 \mathrm{M} \mathrm{CaCl}_{2}$ was used.

The humic acid-coated illites and montmorillonites were prepared by dissolving humic acid in $1 \mathrm{~L}$ of $0.5 \mathrm{M} \mathrm{KCl}$ or $\mathrm{CaCl}_{2}$ solution, followed by mixing with $10 \mathrm{~g}$ of corresponding $\mathrm{Ca}^{2+}$ - or $\mathrm{K}^{+}$-saturated clays for 1 week. The humic acid-coated illite obtained by centrifugation was mixed with either $0.5 \mathrm{M} \mathrm{KCl}$ solution (for $\mathrm{K}^{+}$clays) or $\mathrm{CaCl}_{2}$ solution (for $\mathrm{Ca}^{2+}$-saturated clays) three times to saturate the cation exchange sites in humic acid and then washed repeatedly (20 times) with Mill-Q water until neither light brown-colored humic substances in supernatants nor humic acid particulates accumulating on the top of the clay after centrifugation were visualized. Controls were also prepared but without humic acid. The humic acid-coated clays are hereafter referred to as $\mathrm{HA}_{1}-\mathrm{K}^{+}$-illite, $\mathrm{HA}_{2}-\mathrm{K}^{+}$-illite, $\mathrm{HA}_{1}-\mathrm{Ca}^{2+}{ }_{-}$-illite, $\mathrm{HA}_{2}-\mathrm{Ca}^{2+}$-illite, $\mathrm{HA}_{1}-\mathrm{K}^{+}$-montmorillonite, $\mathrm{HA}_{2}-\mathrm{K}^{+}$-montmorillonite, $\mathrm{HA}_{1}-\mathrm{Ca}^{2+}$-montmorillonite, and $\mathrm{HA}_{2}-\mathrm{Ca}^{2+}$-montmorillonite.

Sorbent Characterization. $\mathrm{HA}_{1}$ and $\mathrm{HA}_{2}$ were subjected to ${ }^{13} \mathrm{C}$ NMR analysis (25) to obtain their chemical group distribution. All tested humic acids were treated with dilute hydrofluoric and hydrochloric acids to reduce ash and paramagnetic contents that would interfere with the acquisition of well-resolved NMR spectra. The NMR data were acquired using a ramp cross-polarization pulse program with magic angle spinning (MAS) on a Bruker Avance $400 \mathrm{MHz}$ NMR spectrometer. The spectra were acquired at a frequency of $75 \mathrm{MHz}$ for ${ }^{13} \mathrm{C}$ and 400 $\mathrm{MHz}$ for ${ }^{1} \mathrm{H}$, a MAS rate of $13 \mathrm{kHz}$, a contact time of $2 \mathrm{~ms}$, a $1 \mathrm{~s}$ recycle delay, approximately 25000 scans per sample, and line broadening of $50 \mathrm{~Hz}$. Structural carbons determined were aliphatic carbon ( $0-50 \mathrm{ppm})$, alcohols, amines, carbohydrates, ethers, methoxy and acetal carbons (50-112 ppm), aromatic carbons (112-145 ppm), phenolic carbons (145-163 ppm), and carboxyl and carbonyl carbons (163-215 ppm).

Humic acids and clays were used as prepared and received, respectively, for surface area and pore volume analyses by nitrogen gas adsorption, and measurements were made with an Autosorb-1 instrument (Quantachrome Crop). The multipoint Brunauer-EmmettTeller method was used to calculate the surface area (26). The BarrettJoyner-Halenda method was used to calculate the mesopore and macropore volumes (26). The surface charge density (SCD) of sorbents was determined by the method recommended by Naidu et al. (27).

Sorption Isotherms. Sorption experiments of $\mathrm{K}^{+}$-saturated and humic acid-modified illites and montmorillonites were conducted using a batch equilibration method using $0.01 \mathrm{M} \mathrm{KCl}$ as the background solution and $100 \mu \mathrm{g} \mathrm{mL}^{-1} \mathrm{NaN}_{3}$ as a biocide. The same procedures were employed for the sorption experiments for $\mathrm{Ca}^{2+}$-saturated and humic acid-modified illites and montmorillonites. In the latter experiments, $0.05 \mathrm{M} \mathrm{CaCl}_{2}$ was used alternatively.

The $\mathrm{pH}$ was adjusted to 4 in order to study the adsorption behavior of 2,4,6-TCP. At this $\mathrm{pH}$, more than $99 \%$ of 2,4,6-TCP existed as the neutral form, if the $\mathrm{p} K_{\mathrm{a}}$ of 6.0-7.4 was considered (23).

Humic acid-modified and unmodified $\mathrm{Ca}^{2+}$ - or $\mathrm{K}^{+}$-illite and -montmorillonite were weighed into glass centrifuge tubes $(0.1 \mathrm{~g}), 20 \mathrm{~mL}$ of initial solutions of 2,4,6-TCP at different concentrations was added, and the tubes were closed with Teflon-lined screw caps. The tubes were then shaken end-over-end for $24 \mathrm{~h}$ at room temperature $\left(20 \pm 5^{\circ} \mathrm{C}\right)$, followed by centrifugation at $10000 \mathrm{~g}$ for $20 \mathrm{~min}$ (for the adsorption on humic acid only) and $1000 \mathrm{~g}$ for $30 \mathrm{~min}$ (for adsorption on humic acid-modified and unmodified $\mathrm{Ca}^{2+}$ - or $\mathrm{K}^{+}$-illite and -montmorillonite), respectively. After centrifugation, an aliquot $(1 \mathrm{~mL})$ of supernatant was transferred to a clean vial for HPLC analysis.

Desorption. The background solution for desorption experiments was prepared by mixing the $0.01 \mathrm{M} \mathrm{KCl}$ and $100 \mu \mathrm{g} \mathrm{mL}^{-1} \mathrm{NaN}_{3}$ with test sorbents using the same solid-to-solution ratio as described previously but without 2,4,6-TCP. Then, the suspension was mixed for the identical length of time used for the desorption experiments. After the appropriate time of mixing, the bottle was centrifuged at $10000 \mathrm{~g}$ for $20 \mathrm{~min}$ (for humic acid) and $1000 \mathrm{~g}$ for $30 \mathrm{~min}$ (for clays), and the supernatant was collected for use as the background solution for desorption experiments. By using this background solution, the solution chemistry was not changed during the desorption process. Desorption experiments were conducted in sequential decant-refill steps immediately following the completion of sorption experiments. At the end of sorption experiments, solids were separated from the aqueous solution by centrifugation and a $1 \mathrm{~mL}$ aliquot of supernatant was withdrawn from each vial for HPLC analysis. Then, $4 \mathrm{~mL}$ of the remaining supernatant was replaced with the same volume of desorption background solution. After dilution, the vials were shaken for 3 days. The suspension was centrifuged, and a $1 \mathrm{~mL}$ aliquot of supernatant was extracted for analysis. The above process was repeated for two more cycles. The 2,4,6-TCP concentration present in the supernatant 
Table 1. Characteristics of Sorbents ${ }^{a}$

\begin{tabular}{|c|c|c|c|c|}
\hline & $\begin{array}{l}\text { surface area } \\
\left(\mathrm{m}^{2} \mathrm{~g}^{-1}\right)\end{array}$ & $\begin{array}{c}\text { pore size } \\
(\AA)\end{array}$ & $\begin{array}{c}\text { CEC } \\
\left(\mathrm{cmol} \mathrm{kg}^{-1}\right)\end{array}$ & 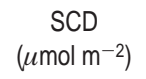 \\
\hline$H A_{1}$ & $50.6(1.33)$ & $19.7(0.32)$ & $38.8(0.43)$ & $0.429(0.015)$ \\
\hline $\mathrm{HA}_{2}$ & $29.5(0.98)$ & $31.4(0.45)$ & $21.8(0.45)$ & $0.247(0.005)$ \\
\hline K-illite & $34.6(1.11)$ & $94.4(0.89)$ & $83.7(1.62)$ & $0.986(0.024)$ \\
\hline $\mathrm{HA}_{1}-\mathrm{K}$-illite & $52.1(1.25)$ & $69.3(1.35)$ & $71.7(1.59)$ & $0.810(0.028)$ \\
\hline $\mathrm{HA}_{2}-\mathrm{K}$-illite & $33.1(1.04)$ & $77.5(1.85)$ & $78.7(1.94)$ & $0.889(0.024)$ \\
\hline Ca-illite & $33.2(0.33)$ & $85.9(1.69)$ & $87.2(0.68)$ & $1.05(0.046)$ \\
\hline $\mathrm{HA}_{1}$-Ca-illite & $49.8(0.92)$ & $65.3(1.23)$ & $75.8(1.32)$ & $0.855(0.033)$ \\
\hline $\mathrm{HA}_{2}$-Ca-illite & $34.2(0.15)$ & $73.2(1.37)$ & $83.8(2.11)$ & $0.992(0.035)$ \\
\hline K-montmorillonite & $34.7(0.41)$ & $83.2(1.46)$ & 115 (3.32) & $1.36(0.058)$ \\
\hline $\mathrm{HA}_{1}-\mathrm{K}$-montmorillonite & $58.6(1.56)$ & $52.2(1.03)$ & 98 (2.24) & $1.11(0.042)$ \\
\hline $\mathrm{HA}_{2}-\mathrm{K}$-montmorillonite & $41(0.44)$ & $67.1(1.44)$ & $105(2.32)$ & $1.17(0.046)$ \\
\hline Ca-montmorillonite & $42.2(0.52)$ & $80.9(1.64)$ & $134(2.55)$ & $1.65(0.061)$ \\
\hline $\mathrm{HA}_{1}$-Ca-montmorillonite & $65(0.63)$ & $48.5(0.99)$ & $112(2.61)$ & $1.32(0.044)$ \\
\hline $\mathrm{HA}_{2}$-Ca-montmorillonite & $46(0.67)$ & $55.4(0.97)$ & $123(2.16)$ & $1.46(0.039)$ \\
\hline
\end{tabular}

${ }^{a}$ Numbers in parentheses are standard errors.

after each desorption cycle was determined by HPLC analysis. Desorbed 2,4,6-TCP was calculated at each desorption stage. The amount of 2,4,6TCP remaining on sorbents at each desorption stage was calculated as the difference between the initial sorbed amount and the final desorbed amount. Both of the duplicates, rather than the average for each experiment, were reported on the isotherms.

The concentrations of 2,4,6-TCP in the sorption/desorption supernatants were determined by a Hewlett-Packard model 1100 gradient HPLC system equipped with an autoinjector and photodiode array UVvis absorption detector and an extended polar selectivity reversed-phase column ( $15 \mathrm{~cm}$ by $4.6 \mathrm{~mm}$ i.d.). The absorption wavelength was 254 $\mathrm{nm}$. The mobile phase was $75 / 25$ (volume ratio) methanol/water, and the flow rate was $1.0 \mathrm{~mL} \mathrm{~min}^{-1}$. Concentrations of pesticide sorbed on clay vs those in aqueous solution were used to construct isotherms with the sorbed mass calculated by the difference between the initial and the equilibrium solute concentration in aqueous solution.

Data Analysis. All sorption and desorption data were fitted to the Freundlich equation $S=K_{\mathrm{f}} C^{N}$, and the isotherm parameters for sorption and desorption were calculated by the logarithmic form of Freundlich equation: $\log S=\log K_{\mathrm{f}}+N \log C$, where $S$ is the sorbed concentration and $C$ is the equilibrium aqueous concentration of 2,4,6TCP. The $K_{\mathrm{f}}$ and $N$ values are the Freundlich coefficients, and the latter is often used as the index of isotherm nonlinearity. Because the units of $K_{\mathrm{f}}$ depend on the $N$ value for a given sample, $K_{\mathrm{f}}$ values cannot be compared between different isotherms. However, the $K_{\mathrm{f}}$ values from different isotherms can be compared with each other after normalizing $C$ by the aqueous solubility of the sorbate $\left(C w_{2,4,6-\mathrm{TCP}}=434 \mathrm{mg} \mathrm{L}^{-1}\right)$. This normalization generates the modified Freundlich parameter, $K_{\mathrm{f}}^{\prime}$, which allowed us to compare $K_{\mathrm{f}}^{\prime}$ values from different isotherms and can be a proper factor to evaluate the sorption capacity of sorbents.

The ratio of Freundlich exponents of desorption to that of sorption, $N_{\mathrm{d}} / N_{\mathrm{s}}$ (subscripts $\mathrm{d}$ and $\mathrm{s}$ refer to as desorption and sorption, respectively), was calculated and used as an indicator of desorption hysteresis (hysteresis index, $\mathrm{HI}$ ). If both $N_{\mathrm{d}}$ and $N_{\mathrm{s}}$ values are less than 1 , the lower the $N_{\mathrm{d}} / N_{\mathrm{s}}$, the higher the hysteresis (i.e., the sorbates are more difficult to be desorbed). This method has been applied to explain chemical desorption behavior by other investigators $(28-31)$. However, when both $N_{\mathrm{d}}$ and $N_{\mathrm{s}}$ values are greater than 1 , more nonlinear sorption (higher $N$ ) is connected with desorption hysteresis. Hence, in this condition $\left(N_{\mathrm{d}}>1, N_{\mathrm{s}}>1\right.$, and $\left.N_{\mathrm{d}} / N_{\mathrm{s}}>1\right)$, the greater the HI values, the more resistant to desorption.

\section{RESULTS AND DISCUSSION}

Sorbent Characteristics. The surface area, mesopore volume, CEC, and SCD of sorbents are listed in Table 1. As can be seen from this table, $\mathrm{HA}_{1}$ had a larger surface area as compared to $\mathrm{HA}_{2}$. The coating of $\mathrm{HA}_{1}$ increased the surface area of clays; however, $\mathrm{HA}_{2}$ showed a minor effect on the surface area of clays. A smaller pore size was observed for two humic acids.
Illites had relatively larger pore sizes. The coating of humic acids led to the obvious decrease of clay pore size. Some humic acid molecules may have entered into the pores of the clays, and the coating may have diminished the original pore size of clays. Humic acids had the smaller CEC values; however, clays had the larger CEC values. Modification of humic acid on clay decreased the CEC values of clays. SCDs were smaller for HAs as compared to those clays, and the coating of humic acids on clays resulted in the decrease of SCD.

Sorption. Apparent sorption equilibrium was achieved within $20 \mathrm{~h}$ for all of the sorbents evaluated. No obvious increase in sorption was observed from a $24 \mathrm{~h}$ to 7 day sorption period for all sorbents. Hence, in the following steady state sorption procedure, $24 \mathrm{~h}$ was selected for sorption.

Sorption isotherms of 2,4,6-TCP by $\mathrm{HA}_{1}, \mathrm{HA}_{2}, \mathrm{~K}^{+}$-montmorillonite, $\mathrm{Ca}^{2+}$-montmorillonite, $\mathrm{K}^{+}$-illite, and $\mathrm{Ca}^{2+}$-illite are shown in Figure 1. Nonlinear adsorption isotherms were observed for all sorbents. All sorption isotherms were fit to the Freundlich equation (shown as the solid lines in Figure 1). The results from Freundlich fittings are listed in Table 2. For 2,4,6TCP, $\mathrm{HA}_{1}$ was a more effective sorbent than $\mathrm{HA}_{2}$. $\mathrm{HA}_{1}$ had a higher ratio of aromatic component concentration to aliphatic component concentration (Table 3 ), and the adsorbed amount of 2,4,6-TCP by $\mathrm{HA}_{1}$ was almost two times than that adsorbed by $\mathrm{HA}_{2}$ (Figure 1a), especially at the higher concentration of 2,4,6-TCP. With regard to clays, the sorption of 2,4,6-TCP on $\mathrm{K}^{+}$- and $\mathrm{Ca}^{+}$-illite was much greater than that on $\mathrm{K}^{+}$- and $\mathrm{Ca}^{2+}$ montmorillonite. The lower charge density illite manifests greater sorption power as compared with the corresponding higher charge density montmorillonite (Table 1). The lower charge clay apparently has the large exposed areas, which are responsible for the reaction between the clay siloxane surfaces and the functional group of 2,4,6-TCP, thereby contributing more favorable pesticide adsorption domains. The sorption followed the order: $\mathrm{K}^{+}$-illite $>\mathrm{Ca}^{2+}$-illite $>\mathrm{K}^{+}$-montmorillonite $>\mathrm{Ca}^{2+}$-montmorillonite (Table 4). The high affinity of $\mathrm{K}^{+}$clays for sorption of 2,4,6-TCP is apparent because of smaller enthalpy of hydration of $\mathrm{K}^{+}$(as compared with $\mathrm{Ca}^{2+}$ ), which shows less inhibition effect on the interaction between pesticide functional groups (e.g., $-\mathrm{Cl},-\mathrm{NO}_{2}$, and $-\mathrm{CN}$ ) and the exchangeable cation (29). The comparative lower adsorption of 2,4,6-TCP by $\mathrm{Ca}^{2+}$-saturated clays is attributed to the larger hydration sphere around $\mathrm{Ca}^{2+}$, which obscured a greater portion of the neutral siloxane surface, thereby reducing hydrophobic interactions between these surfaces and the pesticide (12).

2,4,6-TCP Sorption by Humic Acid-Modified Clay. 2,4,6TCP sorption isotherms of humic acid-modified $\mathrm{K}^{+}$and $\mathrm{Ca}^{2+}$ clays are shown in Figure 2 along with isotherms of unmodified ones. The sorption isotherms were nonlinear for both humic acid-modified montmorillonite and illite and unmodified ones. As compared with the unmodified $\mathrm{Ca}^{2+}, \mathrm{K}^{+}$-montmorillonite, modification of humic acid on montmorillonite, slightly increased the sorption nonlinearity parameters (Table 4). However, humic acid-modified illites showed the significant increase of the sorption nonlinearity and $K_{\mathrm{f}}^{\prime}$ values as compared with the unmodified illites (Table 4). Murphy et al. (32) observed the similar results. Modification of humic acids to clays may induce changes of both mineral surface characteristics and humic acid structure (32), with changes for different clays.

In addition, modification of humic acid increased the adsorption ability of clays. Because the sorption ability of $\mathrm{HA}_{1}$ was stronger than that of $\mathrm{HA}_{2}$, the sorption amount of 2,4,6-TCP on $\mathrm{HA}_{1}$-modified clays was greater than that on $\mathrm{HA}_{2}$-modified clays (Figure 2 and Table 4 ). 

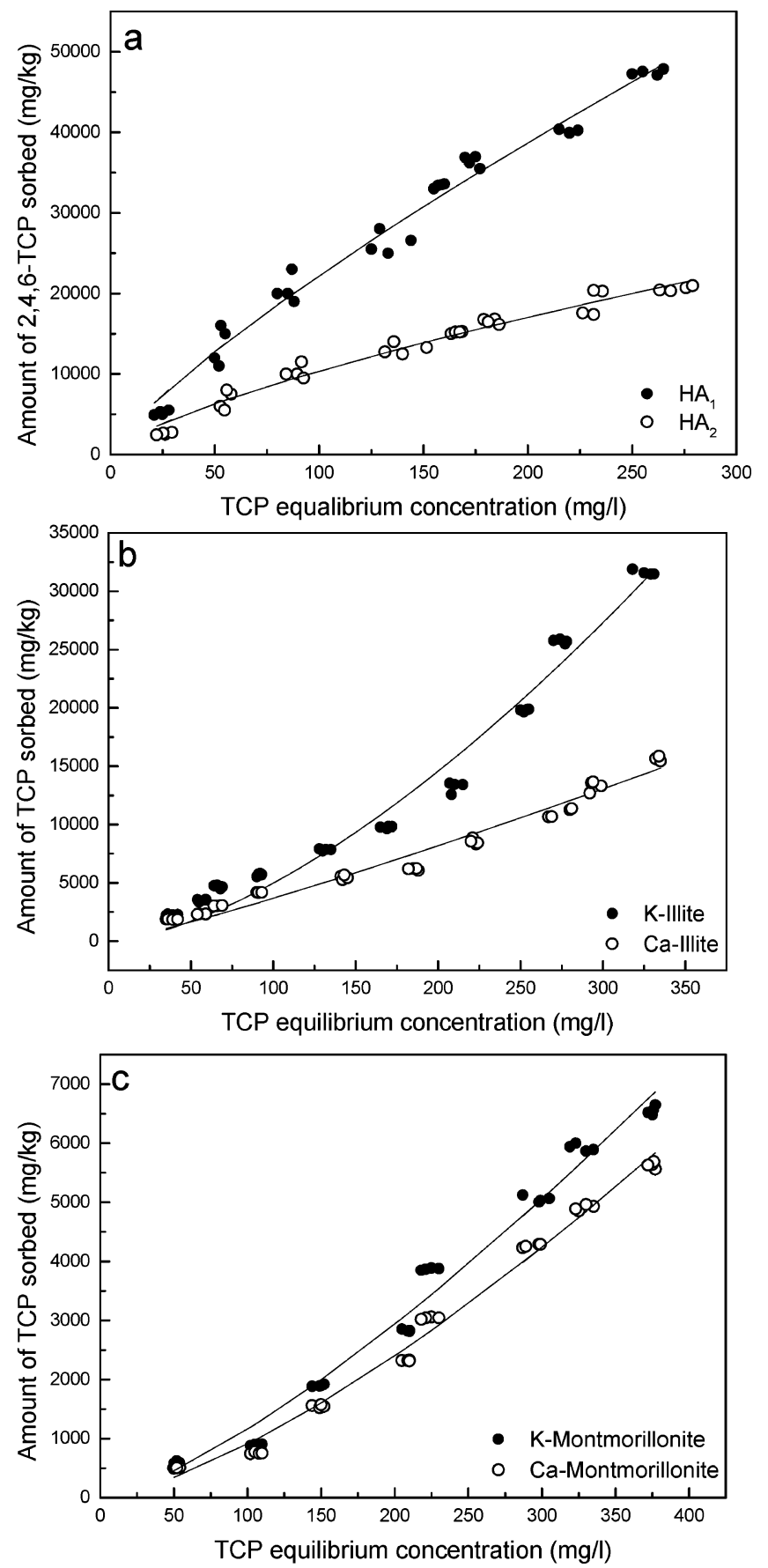

Figure 1. Sorption isotherms of 2,4,6-TCP at pH 4.0 on $\mathrm{HA}_{1}$ and $\mathrm{HA}_{2}$ (a); on $\mathrm{K}^{+}$-illite and $\mathrm{Ca}^{2+-i l l i t e ~(b) ; ~ a n d ~ o n ~} \mathrm{~K}^{+}$-montmorillonite and $\mathrm{Ca}^{2+}$ montmorillonite (c).

Desorption of 2,4,6-TCP. Data of 2,4,6-TCP desorption from humic acids, clays, and humic acid-modified clays fitted the Freundlich model well. Desorption is commonly observed to be biphasic, involving a relatively fast initial release of sorbed 2,4,6-TCP and increasingly slower release as desorption proceeds. Hysteresis is conceptually considered as the results of binding in two different areas: site specific binding and physical entrapment. Differences in hysteresis were observed between the initial concentrations and between the different sorbents. For example, at lower initial concentrations of 2,4,6-TCP, desorption isotherm $N$ values were smaller than those at high concentrations of 2,4,6-TCP for all humic acids (Figure 3). This is as expected, because there were only a limited number of high energy sites in SOM that could be filled first and the
Table 2. Sorption Nonlinearity Parameters of Humic Acids, Clays, and Humic Acid-Modified-Clay Complexes ${ }^{a}$

\begin{tabular}{|c|c|c|c|}
\hline \multirow[b]{2}{*}{ sorbent } & \multicolumn{3}{|c|}{ Freundlich adsorption parameters } \\
\hline & $\log K_{f}^{\prime}$ & $N_{\mathrm{s}}$ & $r^{2}$ \\
\hline 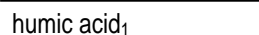 & $4.91(4.42-5.33)$ & $0.717(0.623-0.804)$ & 0.994 \\
\hline humic $\operatorname{acid}_{2}$ & $53(4.14-4.9$ & $0.819(0.703-0.912)$ & 0.992 \\
\hline Ca-illite & $4.23(3.91-4.54)$ & $1.08(0.926-1.24)$ & 0.992 \\
\hline$H A_{1}$-Ca-illite & $4.64(4.02-5.29)$ & $1.22(1.04-1.45)$ & 0.994 \\
\hline $\mathrm{HA}_{2}$-Ca-illite & $4.32(3.96-4.66)$ & $1.15(0.986-1.347)$ & 0.987 \\
\hline K-illite & $4.56(4.09-4$. & $1.15(0.886-0.897)$ & 0.998 \\
\hline$H A_{1}-$ K-illite & $5.05(4.44-5.67)$ & $1.59(0.974-2.24)$ & 0.996 \\
\hline $\mathrm{HA}_{2}-\mathrm{K}$-illite & $4.71(4.32-5.14)$ & $1.56(0.986-2.34)$ & 0.955 \\
\hline Ca-montmorillonite & $3.82(3.55-4.14)$ & $1.34(1.09-1.65)$ & 0.994 \\
\hline $\mathrm{HA}_{1}$-Ca-montmorillonite & $4.03(3.58-4.55)$ & $1.37(1.03-1.74)$ & 0.985 \\
\hline $\mathrm{HA}_{2}$-Ca-montmorillonite & $3.89(3.29-4.52)$ & $1.39(0.95-1.77)$ & 0.991 \\
\hline K-montmorillonite & $3.93(3.42-4.45)$ & $1.41(0.89-1.86)$ & 0.995 \\
\hline $\mathrm{HA} \mathrm{A}_{1}-\mathrm{K}$-montmorillonite & $4.09(3.77-4.43)$ & $1.48(0.95-1.88)$ & 0.995 \\
\hline $\mathrm{HA}_{2}-\mathrm{K}$-montmorillonite & $4.05(3.86-4.34)$ & $1.44(0.85-2.07)$ & 0.965 \\
\hline
\end{tabular}

${ }^{a}$ Numbers in parentheses are $95 \%$ confidence intervals.

Table 3. Properties of the Humic Acids ${ }^{a}$

\begin{tabular}{lcccccccc}
\hline & & \multicolumn{9}{c}{ peak area } & & \\
\cline { 3 - 7 } & & & $0-100$ & $100-165$ & $0-240$ & Aro-C & Ali-C & Aro-C/ \\
& C (\%) & $\mathrm{N}(\%)$ & ppm & ppm & ppm & (\%) & Ali-C \\
\hline $\mathrm{HA}_{1}$ & 65.5 & 1.74 & 6.6 & 93 & 123.4 & 75.4 & 8.5 & 8.87 \\
$\mathrm{HA}_{2}$ & 54.7 & 3.82 & 61.2 & 95.7 & 182 & 52.6 & 33.6 & 1.57
\end{tabular}

${ }^{a}$ Aro-C means aromatic carbon, and Ali-C means aliphatic carbon.

proportion of 2,4,6-TCP molecules in these sites was higher at lower concentrations. At lower concentrations of 2,4,6-TCP, high affinity of sorbents made the desorption more difficult. In contrast, at high concentrations of 2,4,6-TCP, the limited high energy sites were saturated and the proportion of resistant fractions of sorbent would be lower at high concentrations than that at lower concentrations; thus, overall desorption was easier. However, at the highest concentrations of 2,4,6-TCP, the $N$ values of 2,4,6-TCP desorption isotherm tended to decrease. This may be due to the creation of more holes or sorption sites upon the removal of 2,4,6-TCP molecules (11). With the concentration increase of sorbate, humic acids may be swelled and converted to the rubbery phase (33). New holes and sorption sites can trap more sorbate molecules, which are resistant to desorption. Consequently, at the highest concentrations, desorption isotherms for all sorbents became more nonlinear as compared to that from the adjacent, few lower concentration points (Figure 3a,b).

Desorption hysteresis is conceptually considered to be the result of irreversibly bound 2,4,6-TCP on sorbents. The ratio of Freundlich exponents of desorption to sorption, $N_{\mathrm{d}} / N_{\mathrm{s}}$, was calculated, which was used as an indicator of desorption hysteresis. Previous reports demonstrated that some organic matters, such as Canada peat, exhibited no measurable desorption hysteresis. However, mature organic matters and kerogen exhibited appreciable desorption hysteresis (34). In our desorption experiments, humic acids with different origins showed obvious desorption hysteresis, which was evidenced by lower $N_{\mathrm{d}} / N_{\mathrm{s}}$ values (HI values). More nonlinear sorption (low $\mathrm{HI}$ value) is associated with pronounced desorption hysteresis under the conditions of the Freundlich exponents of less than 1. As for the two humic acids investigated in this paper, both $N_{\mathrm{d}}$ and $N_{\mathrm{s}}$ values were less than 1 ; therefore, the lower desorption HI values, the more resistant to desorption. Figure 4 showed the HI value of 2,4,6-TCP in different sorbents. Table 5 lists the $P$ 
Table 4. $P$ Values of $\log K_{f}^{\prime}$ and Ns for Different Sorbents ${ }^{a}$

\begin{tabular}{|c|c|c|c|c|c|c|c|c|}
\hline \multirow[t]{2}{*}{ comparison } & \multicolumn{8}{|c|}{ sorbents } \\
\hline & $\mathrm{HA}_{1}$ vs & Ca-illite vs & Ca-illite vs & $\mathrm{HA}_{1}$-Ca-illite vs & K-illite vs & K-illite vs & $H A_{1}-K$-illite vs & K-illite vs \\
\hline & $\mathrm{HA}_{2}$ & $\mathrm{HA}_{1}$-Ca-illite & $\mathrm{HA}_{2}$-Ca-illite & $\mathrm{HA}_{2}$-Ca-illite & $\mathrm{HA}_{1}$-K-illite & $\mathrm{HA}_{2}$-K-illite & $\mathrm{HA}_{2}$-K-illite & Ca-illite \\
\hline $\log K_{f}^{\prime}$ & $0.0015^{b}$ & $0.0001^{b}$ & $0.0037^{b}$ & $0.0001^{b}$ & $0.0001^{b}$ & $0.0035^{b}$ & $0.0028^{b}$ & $0.0026^{b}$ \\
\hline \multirow[t]{3}{*}{$\mathrm{Ns}$} & $0.0023^{b}$ & $0.0001^{b}$ & $0.0013^{b}$ & $0.0018^{b}$ & $0.0001^{b}$ & $0.0001^{b}$ & 0.0543 & $0.0041^{b}$ \\
\hline & & Ca-mont vs & Ca-mont vs & $\mathrm{HA}_{1}$-Ca-mont vs & K-mont vs & K-mont vs & $\mathrm{HA}_{1}$-K-mont vs & K-mont vs \\
\hline & & $\mathrm{HA}_{1}$-Ca-mont & $\mathrm{HA}_{2}$-Ca-mont & $\mathrm{HA}_{2}$-Ca-mont & $\mathrm{HA}$-K-mont & $\mathrm{HA}_{2}-\mathrm{K}$-mont & $\mathrm{HA}_{2}-\mathrm{K}$-mont & Ca-mont \\
\hline $\log K_{f}^{\prime}$ & & $0.0034^{b}$ & $0.0046^{b}$ & 0.0055 & $0.0373^{b}$ & $0.00433^{b}$ & 0.0721 & $0.0465^{b}$ \\
\hline Ns & & 0.0625 & 0.0544 & 0.0693 & $0.0043^{b}$ & $0.0048^{b}$ & 0.0644 & $0.0042^{b}$ \\
\hline
\end{tabular}

${ }^{a}$ Montmorillonite was referred to here as mont. ${ }^{b}$ Significant at the 0.05 probability level.
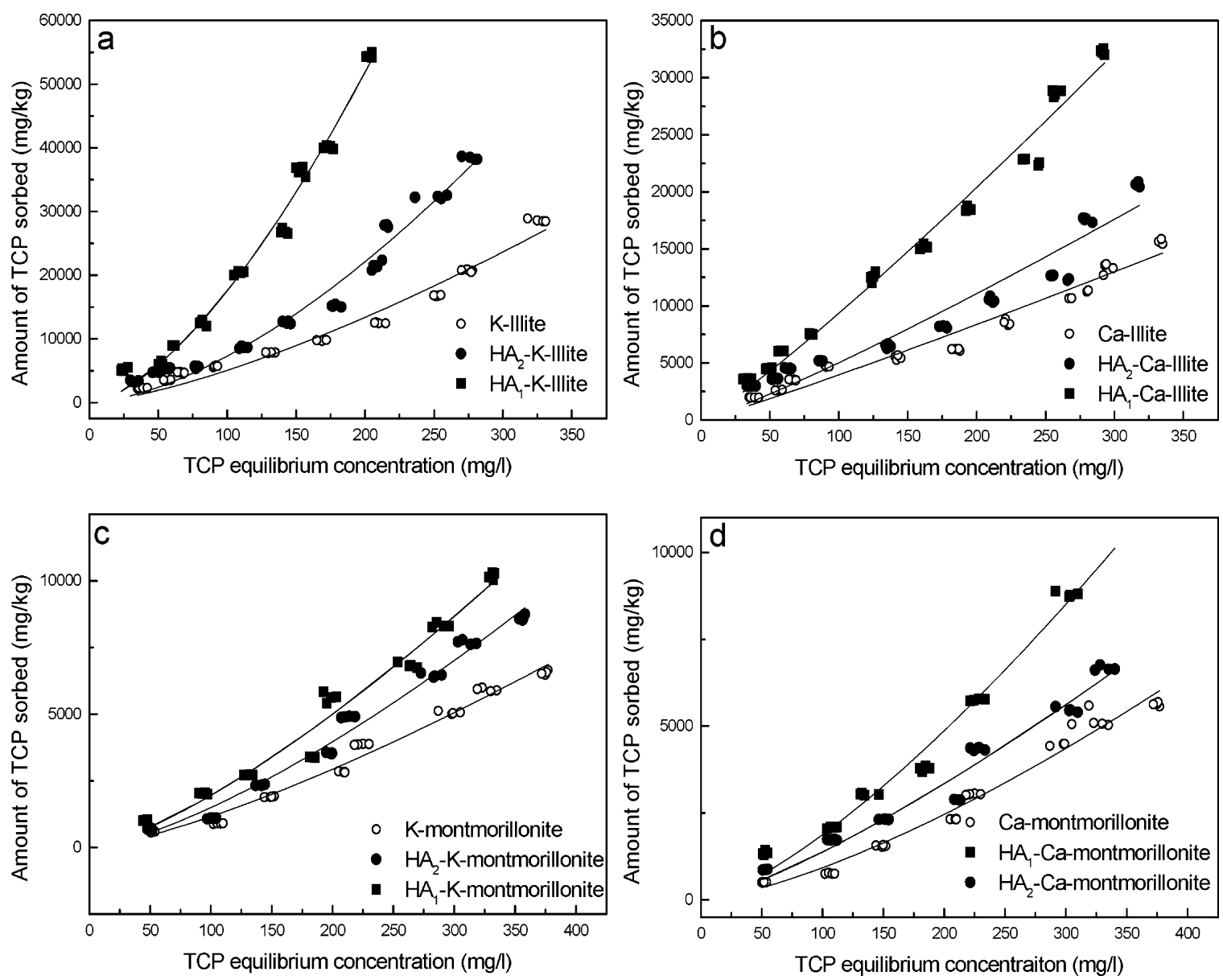

Figure 2. Sorption isotherms of 2,4,6-TCP at pH 4.0 on HA-modified $\mathrm{K}^{+}$-illite and $\mathrm{K}^{+}$-illite (a); on HA-modified $\mathrm{Ca}^{2+}$-illite and $\mathrm{Ca}^{2+}$-illite (b); on $\mathrm{HA}^{-}$ modified $\mathrm{K}^{+}$-montmorillonite and $\mathrm{K}^{+}$-montmorillonite $(\mathbf{c})$; and on $\mathrm{HA}$-modified $\mathrm{Ca}^{2+}$-montmorillonite and $\mathrm{Ca}^{2+}$-montmorillonite (d).

values for $\mathrm{HI}$ calculated by the $F$ test. From Figure 4a, we could see that $\mathrm{HA}_{2}$ had larger $\mathrm{HI}$ values than $\mathrm{HA}_{1}$ in higher concentrations of 2,4,6-TCP. This result indicated that a high concentration of 2,4,6-TCP sorbed on $\mathrm{HA}_{1}$ was more difficult to be desorbed, as compared to $\mathrm{HA}_{2}$. However, in relatively low concentrations, $\mathrm{HI}$ values for $\mathrm{HA}_{1}$ and $\mathrm{HA}_{2}$ were not different, which meant that $\mathrm{HA}_{1}$ and $\mathrm{HA}_{2}$ had the similar ability on binding or entrapping 2,4,6-TCP in this concentration. As can be seen from Table $3, \mathrm{HA}_{1}$ had a higher content of aromatic components $(75.4 \%)$ and a lower content of aliphatic $\mathrm{C}(8.5 \%)$, and $\mathrm{HA}_{2}$ had a relatively higher content of aliphatic $\mathrm{C}(33.6 \%)$ and a lower content of aromatic C (52.6\%). According to Xing's result, the condensed domain of sorbent may be primarily composed of aromatic moieties. Dual-mode sorption held that organic matter in soil consists of two types of amorphous domains. The domains are characterized as expanded and condensed, analogous to rubbery and glassy synthetic polymers, respectively. The sorption of organic pollutants to the expanded "rubbery-like" domain generates linear isotherms due to partitioning while nonlinear isotherms are observed for the condensed "glassy-like" domain (34). On the basis of the component of humic acid and the nonlinearity of sorption isotherm, $\mathrm{HA}_{1}$ appeared to have a relatively more rigid structure (rich in glassy or condensed phase). Because of its rigid SOM structure (high aromatic carbon concentration), a larger proportion of irreversible adsorption sites may exist in $\mathrm{HA}_{1}$, resulting in a higher extent of desorption hysteresis.

As far as clays were concerned, our experimental data indicated that both desorption and sorption Freundlich exponents $\left(N_{\mathrm{d}}\right.$ and $\left.N_{\mathrm{s}}\right)$ of clays were $>1$, which were higher from most of the data reported in the literatures. In this case, the increased nonlinear sorption (high $N_{\mathrm{d}}$ ) was correlated with the increased desorption hysteresis. Accordingly, for these sorbents, the higher the HI values $\left(N_{\mathrm{d}} / N_{\mathrm{s}}>1\right)$, the higher the desorption hysteresis. 


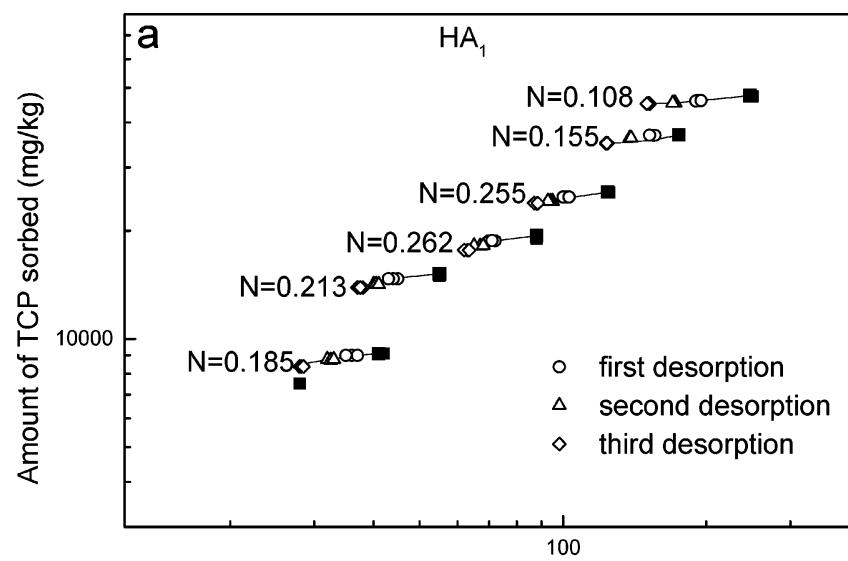

TCP equilibrium concentration $(\mathrm{mg} / \mathrm{l})$

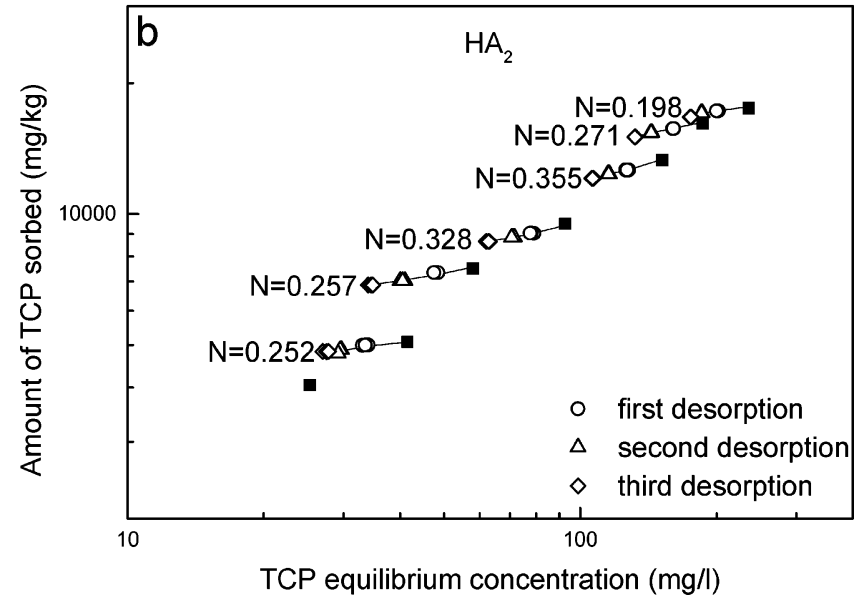

Figure 3. Sorption-desorption of 2,4,6-TCP on $\mathrm{HA}_{1}$ (a) and sorptiondesorption of 2,4,6-TCP on $\mathrm{HA}_{2}$ (b).

Barriuso et al. (26) and $\mathrm{Li}$ et al. (12) have observed similar phenomena. Desorption $\mathrm{HI}$ values and the corresponding $P$ values for clays and humic acid-modified clays are shown in Figure 4 and Table 5. As can be seen from Figure 4, the humic acid-modified $\mathrm{K}^{+}$-illite displayed more obvious desorption hysteresis, as compared with the unmodified $\mathrm{K}^{+}$-illite. With regard to $\mathrm{HA}-\mathrm{K}^{+}$-illite and $\mathrm{K}^{+}$-illite, enlarged $N_{\mathrm{d}} / N_{\mathrm{s}}$ values shed light on a significant desorption hysteresis, which means humic acid modification led to desorption of 2,4,6-TCP further difficult as compared to unmodified illite (Table 5). Nevertheless, desorption hysteresis appeared to display positive reliance on the nonlinearity of adsorption (humic acid-modified illite with higher $N_{\mathrm{s}}$ values showed higher $N_{\mathrm{d}} / N_{\mathrm{s}}$ values too).

As compared to illites, modification of humic acid on montmorillonites slightly improved the $N_{\mathrm{d}} / N_{\mathrm{s}}$ values of montmorillonites. $P$ values of $\mathrm{HI}$ for HA-montmorillonites vs montmorillonites were at the edge of the 0.05 significance level but $<0.05$ (Table 5). This result was in line with the minor influence of humic acid on $N_{\mathrm{s}}$ values of montmorillonites. The observed differences in sorption or desorption between humic acid-modified illite and montmorillonites suggested that the interactions between humic acids and different clays surfaces were different.

Contribution of Organic Carbon Content on the Desorption Hysteresis of 2,4,6-TCP. In our study, humic acid-modified clays containing different contents of organic carbon were prepared by using different clay to humic acid ratios. Desorption hysteresis of 2,4,6-TCP from these complexes was investigated, and the HI values were estimated to evaluate the contribution of humic acid. Modification of humic acid on clays increased
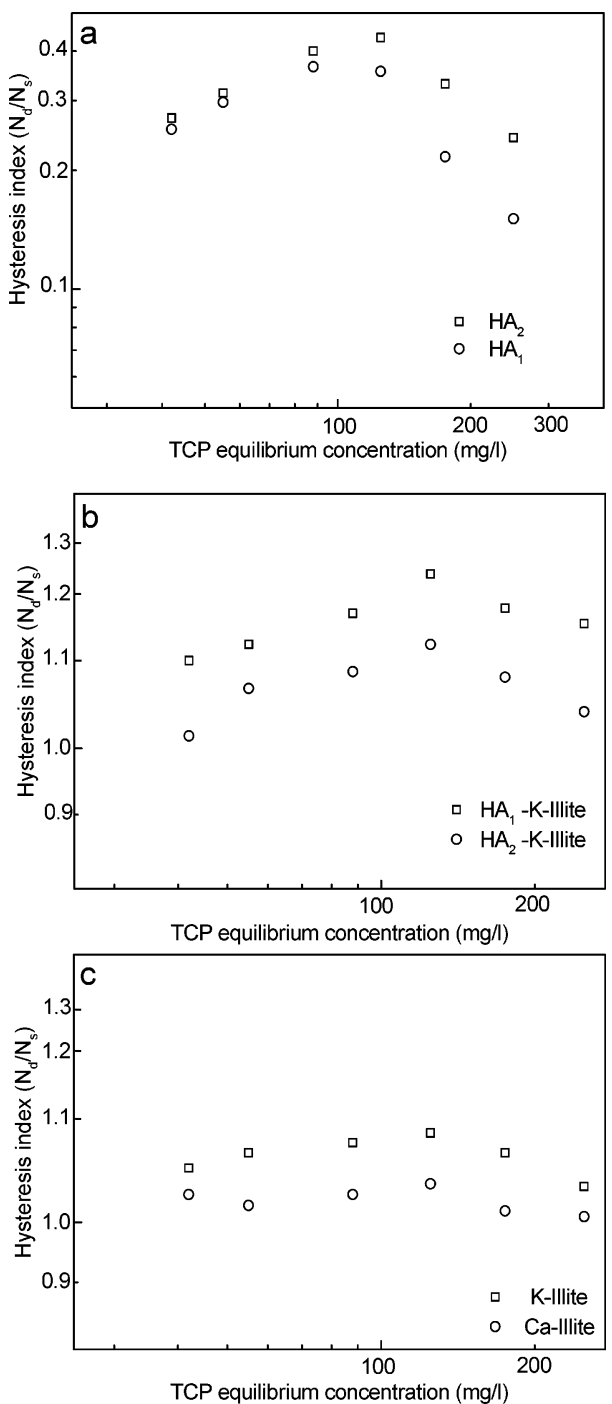

Figure 4. Comparison of $\mathrm{HI}$ of $\mathrm{HA}_{1}$ and $\mathrm{HA}_{2}(\mathbf{a}) ; \mathrm{HA}_{1}-\mathrm{K}^{+-}$-illite and $\mathrm{HA}_{2-}$ $\mathrm{K}^{+}$-illite (b); and $\mathrm{K}^{+}$-illite and $\mathrm{Ca}^{2+}$-illite $(\mathbf{c})$.

Table 5. $P$ Values of $\mathrm{HI}$ for $\mathrm{HA}_{1}, \mathrm{HA}_{2}$, $\mathrm{K}$-Illite, Ca-Illite, $\mathrm{HA}_{1}-\mathrm{K}$-Illite, and $\mathrm{HA}_{2}-\mathrm{K}$-Illite

\begin{tabular}{ccccccc}
\hline & \multicolumn{6}{c}{ TCP equilibrium concentration (mg/L) } \\
\cline { 2 - 7 } sorbent & 42 & 55 & 88 & 125 & 175 & 250 \\
\hline $\mathrm{HA}_{1}$ vs HA & 0.0672 & 0.0587 & 0.0524 & $0.0464^{a}$ & $0.0448^{a}$ & $0.0432^{a}$ \\
$\mathrm{HA}_{1}-\mathrm{K}$-illite vs & $0.0024^{a}$ & $0.0031^{a}$ & $0.0022^{a}$ & $0.0018^{a}$ & $0.0015^{a}$ & $0.0027^{a}$ \\
HA - K-illite & & & & & & \\
K-illite vs & $0.0046^{a}$ & $0.0032^{a}$ & $0.0014^{a}$ & $0.0019^{a}$ & $0.0036^{a}$ & $0.0039^{a}$ \\
Ca-illite & & & & & &
\end{tabular}

a Significant at the 0.05 probability level.

the adsorption ability of clays, and with the increase of humic acid content, the absorbed amount of 2,4,6-TCP increased (Figure 5). Table 6 displays the $P$ values of $K_{\mathrm{f}}^{\prime}$ for different organic $\mathrm{C}$ contents of humic acid clays. The increased amount of 2,4,6-TCP sorbed on humic acid clays was evidenced by the increasing $K_{\mathrm{f}}^{\prime}$ values, which can reflect the sorption capacity of sorbents. As for the HI values, they strongly correlated with the content of organic $\mathrm{C}$ of $\mathrm{HA}_{1}$-modified illite (Figure 5). However, the correlation coefficient obtained for $\mathrm{HA}_{2}$-modified illite was less than that of $\mathrm{HA}_{1}$-modified illite $(P$ values of correlation coefficient for $\mathrm{HA}_{1}$-modified illite vs $\mathrm{HA}_{2}$-modified illite $=0.004)$. The similar result was observed for montmorillonite and HA-modified montmorillonite (data not shown). 

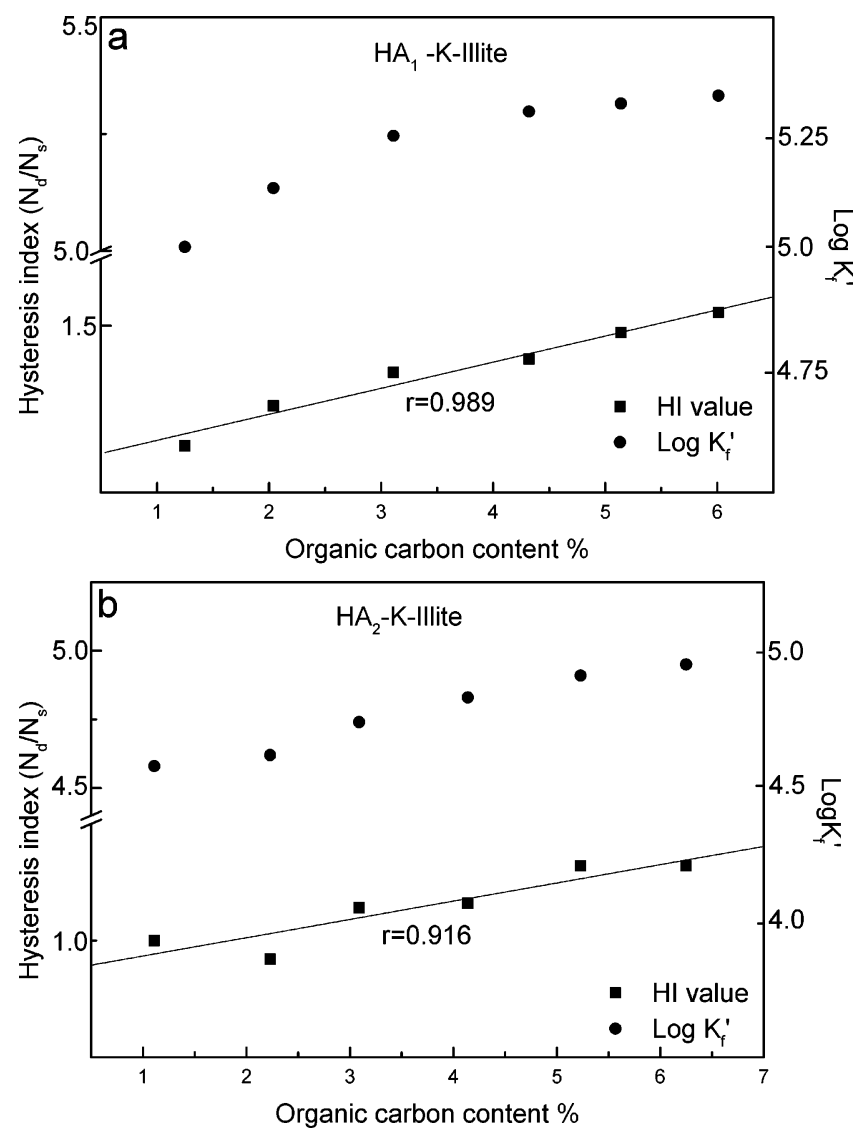

Figure 5. Change of $\mathrm{HI}$ and $K_{f}^{\prime}$ value of $\mathrm{HA}_{1}-\mathrm{K}^{+}$-illite (a) and $\mathrm{HA}_{2}-\mathrm{K}^{+}$-illite (b) with the increase of organic carbon content.

Table 6. $P$ Values of $\mathrm{HI}$ and $\log K_{\mathrm{f}}^{\prime}$ for the Humic Acid-Clay System

\begin{tabular}{|c|c|c|c|c|}
\hline \multirow{3}{*}{$\begin{array}{l}\text { organic carbon } \\
\text { content (\%) }\end{array}$} & \multicolumn{4}{|c|}{ sorbents } \\
\hline & \multicolumn{2}{|c|}{$\mathrm{HA}_{1}$-K-illite } & \multicolumn{2}{|c|}{$\mathrm{HA}_{2}$-K-illite } \\
\hline & $\mathrm{HI}$ & $\overline{\log K_{f}^{\prime}}$ & $\mathrm{HI}$ & $\log K_{f}^{\prime}$ \\
\hline 2 vs $1 \%$ & $0.0031^{a}$ & $0.0144^{a}$ & $0.0252^{a}$ & 0.0522 \\
\hline 3 vs $2 \%$ & $0.0201^{a}$ & $0.0119^{a}$ & $0.0212^{a}$ & $0.0014^{a}$ \\
\hline 4 vs $3 \%$ & $0.0262^{a}$ & $0.0223^{a}$ & $0.0314^{a}$ & $0.0289^{a}$ \\
\hline 5 vs $4 \%$ & $0.0331^{a}$ & $0.0331^{a}$ & $0.0355^{a}$ & $0.0247^{a}$ \\
\hline 6 vs $5 \%$ & $0.0255^{a}$ & $0.0387^{a}$ & $0.0312^{a}$ & $0.0374^{a}$ \\
\hline
\end{tabular}

${ }^{a}$ Significant at the 0.05 probability level.

The gradually increased $\mathrm{HI}$ of $\mathrm{HA}_{1}$ clays suggested that desorption hysteresis was enlarged by increasing $\mathrm{HA}_{1}$ in the humic acid-modified clays. $\mathrm{HA}_{1}$ had a higher content of aromatic components $(75.4 \%)$, and $\mathrm{HA}_{2}$ had a higher content of aliphatic $\mathrm{C}$. These results showed that modification of humic acid on clays not only increased the adsorption ability of clays but also affected the sorption and desorption behaviors of 2,4,6TCP probably due to the differences in the structural characteristics of the humic acid. The humic acid with a higher content of aromatic components mainly contributed to the sorption nonlinearity and desorption hysteresis.

\section{LITERATURE CITED}

(1) Johnson, R.; Sims, J. Influence of surface and subsoil properties on herbicide sorption by Atlantic coastal plain soils. Soil Sci. 1993, 155, 339-348.

(2) Chefetz, B.; Deshmukh, A.; Hatcher, P. Pyrine sorption by natural organic matter. Environ. Sci. Technol. 2000, 34, 2925-2930.
(3) Hundal, L.; Thompson, M.; Laird, D.; Carmo, M. Sorption of phenanthrene by reference smectites. Environ. Sci. Technol. 2001, 35, 3456-3461.

(4) Chiou, C.; Peters, L.; Feed, V. A physical concept of soil-water equilibria for nonionic organic compounds. Science 1979, 206, 831-832.

(5) Chiou, C.; Porter, P.; Schmedding, D. W. Partition equilibria of nonionic organic compounds between soil organic matter and water. Environ. Sci. Technol. 1983, 17, 227-231.

(6) Karickhoff, S.; Brown, D.; Scott, T. A. Sorption of hydrophobic pollutants on natural sediments. Water Res. 1979, 13, 241-248.

(7) Kile, D.; Chiou, C.; Zhou, H.; Li, H.; Xu, O. Partition of nonpolar organic pollutants from water to soil and sediment organic matters. Environ. Sci. Technol. 1995, 29, 1401-1406.

(8) Xing, B.; Pignatello, J. Dual-mode sorption of low-polarity compounds in glassy poly (vinyl chloride) and soil organic matter. Environ. Sci. Technol. 1997, 31, 792-799.

(9) Mingelgrin, U.; Gerstl, Z. Reevaluation of partitioning as a mecha- nism of nonionic chemicals adsorption in soil. J. Environ. Qual. 1983, 12, 1-10.

(10) Chiou, C.; Shoup, T. Soil sorption of organic vapors and effects of humidity on sorptive mechanism and capacity. Environ. Sci. Technol. 1985, 19, 1196-1200.

(11) Ding, G.; Novak, J.; Herbert, S.; Xing, B. Long-tillage effects on soil metolachlor sorption and desorption behavior. Chemosphere 2002, 48, 897-904.

(12) Li, H.; Sheng, G.; Teppen, B.; Johnston, C.; Boyd, S. Sorption and desorption of pesticides by clay minerals and humic acidclay complexes. Soil Sci. Soc. Am. J. 2003, 67, 122-131.

(13) Boyd, S.; Sheng, G.; Teppen, B.; Johnston, C. Mechanisms for the adsorption of substituted nitrobenzenes by smectite clays. Environ. Sci. Technol. 2001, 35, 4227-4234.

(14) Spark, K.; Swift, R. Effect of composition and dissolved organic matter on pesticide sorption. Sci. Total Environ. 2002, 298, 147161.

(15) Sheng, G.; Johnston, C.; Teppen, B.; Boyd, S. Potential contributions of smectite clays and organic matter to pesticide retention in soils. J. Agric. Food. Chem. 2001, 49, 2890-2907.

(16) Pignatello, J.; Xing, B. Mechanisms of slow sorption of organic chemicals to natural particles. Environ. Sci. Technol. 1996, 30, $1-11$.

(17) Alexander, M. How toxic are toxic chemicals in soil? Environ. Sci. Technol. 1995, 29, 2713-2717.

(18) http://www.epa.gov/iris/subst/0122.htm.

(19) Murin, C.; Snoeylnk, V. Competitive adsorption of 2,4-dichlorophenol and 2,4,6-trichlorophenol in the nanomolar to micromolar concentration range. Environ. Sci. Technol. 1979, 13, 305311.

(20) Angelo, E.; Reddy, K. Effect of aerobic and anaerobic conditions on chlorophenol sorption in wetland soils. Soil Sci. Soc. Am. J. 2003, 67, 787-794.

(21) Celis, R.; Cornejo, J.; Hermosin, M.; Koskinen, W. Sorption of atrazine and simazine by model associations of soil colloids. Soil Sci. Soc. Am. J. 1998, 62, 165-171.

(22) Cox, L.; Koskinen, W.; Celis, R.; Yen, P.; Hermosin, M.; Cornejo, J. Sorption of imidacloprid on soil clay mineral and organic components. Soil Sci. Soc. Am. J. 1998, 62, 911-915.

(23) Czaplicka, M. Sources and transformations of chlorophenols in the natural environment. Sci. Total Environ. 2004, 322, 21-39.

(24) Swift, R. In Methods of Soil Analysis Part 3 Chemical Methods; Sparks, D., Ed.; Soil Science Society of America: Madison, WI, 1996; pp 1011-1069.

(25) Gunasekara, A.; Simpson, M.; Xing, B. Identification and characterization of sorption dormains in soil organic matter using structurally modified humic acids. Environ. Sci. Technol. 2003, 37, 852-858.

(26) Han, S.; Kim, M.; Hyeon, T. Direct fabrication of mesoporous carbons using in-situ polymerized silica gel networks as a template. Carbon 2003, 41, 1525-1532. 
(27) Naidu, R.; Bolan, N.; Kookana, R.; Tiller, K. Ionic strength and $\mathrm{pH}$ effects on the sorption of cadmium and the surface charge of soils. Eur. J. Soil Sci. 1994, 45, 419-429.

(28) Barriuso, E.; Laird, D.; Koskinen, W.; Dowdy, R. Atrazine desorption from smectites. Soil Sci. Soc. Am. J. 1994, 58, 16321638.

(29) Yuan, G.; Xing, B. Effects of metal cations on sorption and desorption of organic compounds in humic acids. Soil Sci. 2001, $166,107-115$.

(30) Roy, W.; Krapac, I. Adsorption and desorption of atrazine and deethylatrazine by low organic carbon geologic matereials. $J$. Environ. Qual. 1994, 23, 549-556.

(31) Ma, L.; Southwick, L.; Willis, G.; Selim, H. Hysteretic characteristics of atrazine adsorption-desorption by a Sharkey soil. Weed Sci. 1993, 41, 627-633.

(32) Murphy, E.; Zachara, J.; Smith, S.; Phillips, J.; Wletsma, T. Interaction of hydrophobic organic compounds with mineral- bound humic substances. Environ. Sci. Technol. 1994, 28, 12911299.

(33) Xia, G.; Pignatello, J. Detailed sorption isotherms of polar and apolar compounds in a high-organic soil. Environ. Sci. Technol. 2001, 35, 84-94.

(34) Gunasekara, A.; Xing, B. Sorption and desorption of naphthalene by soil organic matter: Important of aromatic and aliphatic components. J. Environ. Qual. 2003, 32, 240-246.

Received for review November 15,2004 . Revised manuscript received March 6, 2005. Accepted March 9, 2005. This work is supported by the Chinese Academy of Sciences (Grant KZCX2-414) and the National Natural Science Foundation of China (Grants 20237010, 20177030, and 40171086).

JF048106R 